\title{
Research on Teaching Skills Training Mode of Normal Students in Newly-built Local Universities
}

\author{
Huiyun Gao*, Xiaoli Wang \\ Guizhou University of Engineering Science, Bijie 551700, Guizhou, China \\ Email: 499952930@qq.com
}

\begin{abstract}
The training of teaching skills is an important link in the training of normal talents in undergraduate colleges. Based on the training requirements of normal undergraduates, this paper briefly sorts out the problems existing in the training of normal students' teaching skills in newly-built local undergraduate colleges. Then, it explores and establishes appropriate teaching skills training modes and methods, so as to strengthen the teaching skills training level of normal students. Finally, this paper further improves the training quality of normal talents, with an expectation to provide a certain reference basis on the training and teaching of teaching skills for normal students.
\end{abstract}

Keywords: normal students, teaching skills, cooperative education mode, network platform, mechanism

\section{Introduction}

The level of teaching skills of normal graduates is the key factor to measure the quality of training normal talents in undergraduate colleges. In 1992, the Ministry of Education promulgated "The Basic Requirements of Teachers' Vocational Skills Training for Students in Normal Universities (Trial)", and in 1994, the Ministry of Education entrusted Beijing Normal University to draft "The Outline of Teachers' Vocational Skills Training for Students in Normal Universities (Trial)", which clearly pointed out the definition of normal students' teaching skills. "Teaching skills are a series of teaching behaviors adopted by teachers to use professional knowledge and teaching theory to design teaching, use teaching media, compile teaching software, organize teaching activities inside and outside class, and conduct teaching research. Its main contents include skills of teaching design, using teaching media and compiling teaching software, classroom teaching, designing and correcting homework, organizing and guiding extracurricular activities and teaching research" (the Chinese Ministry of Education, 1992; the Chinese Ministry of Education, 1994).

The training of normal students plays an important role in the construction of teaching stuff in China. On August 15, 2013, the Ministry of Education issued "The Interim Measures for the Qualification Examination of Primary and Secondary School Teachers". Since the promulgation of the Measures, teachers' vocational access must pass the teacher qualification examination, and in the teacher qualification examination, the interview process includes examining the applicant's teaching skills such as teaching design, teaching implementation and teaching evaluation (Ministry of Education of the People's Republic of China, 2011; Ministry of Education of the People's Republic of China, 2013).

Due to the various reasons as the imbalance of educational resources and the need for further improvement of educational concepts, the satisfaction of teacher education courses to the vocational skills demand of normal students in local undergraduate colleges needs to be improved, especially there are still many weak problems in the teaching skills training of local newly-built undergraduate colleges (Liu \& Wang, 2019; Wang, 2013; Chen, 2018). Improving normal students' teaching skills is not only the basic demand to ensure the smooth employment of normal students, but also the basic requirement for the development of teacher education in China by exploring the reform of their teaching skills training mode. In this paper, combined with the teaching skills training practice of normal students in a newly-built local university, we explore and establish appropriate teaching skills training modes and methods, so as to strengthen the teaching skills training level of normal students and further improve the training quality of normal talents.

The rest of the paper is organized as follows. The existing problems in training modes are investigated in Section 2 . In Section 3, we present promising suggestions on improving training mode to improve teaching skills training modes. And Section 4 concludes the paper and discuss prospects in future reference.

\section{The existing problems in training modes}

Since the pilot national teacher qualification certificate test, the pass rate of teacher qualification examination for normal students is generally less than $30 \%$ overall. In the first four national teacher qualification examinations, the 
reference number of six provinces have reached 280,800, and the number of people passed was 77200, with a pass rate of only $27.5 \%$. It shows that the teaching ability of normal students is insufficient, and they fail to achieve good results in teacher qualification (Jiang, 2017). Chen (2018) conducts the investigation of 555 normal university students in a local comprehensive university and reveals the imbalance between the supply and demand of teacher education courses. Liu $\&$ Wang (2019) surveys the investigation and research on the current situation of the professional skills training of normal university students in a normal university. The results show that there are still some problems in the professional skills training of normal university students. Wang (2013) also points out that there are some problems in the training of normal students' teaching skills, such as lack of understanding of the new curriculum standard, inaccurate grasp of micro-teaching, weak ability of using multi-body courseware, unclear ideas of course-telling design and weak basic teaching skills. The above survey shows that there is a great contradiction between the expectation value of the teaching skill level of the primary and middle school graduates and the actual level of normal students in the local newly-built applied undergraduate colleges and universities. This contradiction has also aroused the attention of many scholars to the cultivation of teaching skills of normal students. Based on above shortcomings, by considering the current situation of teaching skills training model in a new local undergraduate college compared with actual needs of teaching skills in primary and secondary schools and the requirements of teachers' professional skills training syllabus and teacher education curriculum standards of students in normal schools, this paper puts forward the following five problems.

(1) Compared to the needs of primary and secondary school teachers' teaching skills level and "The Outline of Teachers' Vocational Skills Training for Students in Normal Universities (Trial)" and "The Curriculum Standard of Teacher Education (Trial)", there are still some problems in the current teaching skills training, i.e. insufficient training content and weak pertinence, so it is necessary to further explore and construct a suitable training content system.

(2) Limited by teaching skills training equipment, places and educational practice base, the actual situation of "emphasizing theory, neglecting practice" in teaching skills training is more serious, so it is necessary to further increase the necessary investment in teaching skills training resources, actively explore the "CUGS" cooperative school-running mode, and earnestly strengthen the training of practice links.

(3) The mechanism of carrying out teaching skills training in the whole process and in all orientations during normal school has not yet been formed, so it is necessary to explore and construct a "spiral" teaching skills training mode that runs through the whole process of training.

(4) The admission line of college entrance examination in newly-built undergraduate colleges are low, such that some shortcomings in the subject foundation and learning ability when students enter school, so there is a need to pay attention to teaching skills training and scientifically design teaching skills training programs.

(5) The improvement room in the assessment and evaluation mechanism of teaching skills training, and it is necessary to further explore and form a reasonable assessment and evaluation system so as to be able to continuously feedback and improvement.

\section{Suggestions on improving training modes}

In view of the above problems and shortcomings, it is necessary to reform the content system of new local undergraduate colleges and universities, which against the actual needs of teaching skills in primary and secondary schools, the syllabus of teachers' vocational skills training and the curriculum standards of teachers' education. The recommendations are as follows.

\subsection{Building a scienti ic and reasonable training content system}

According to "The Basic Requirements of Teachers' Vocational Skills Training for Students in Normal Universities", the following six skills are required for teaching.

The teaching plan can be formulated according to the characteristics of the subject.

It can apply the teaching skills of introducing, explaining, asking questions, adapting, consolidating, ending and writing on the blackboard according to the teaching tasks and students' characteristics.

It can correct homework and reasonably evaluate students' grades according to students' actual conditions;

It can make simple teaching tools according to the characteristics of the subject, and has the ability to use modern teaching methods such as slide show, projection, television and microcomputer.

It can organize and guide extracurricular scientific and technological activities related to this major.

It can use professional knowledge and the principles of pedagogy and psychology to carry out teaching research.

When designing and constructing teaching skills training contents, we should comprehensively include the above 
six skills training contents, form a content framework by modules, pay attention to the cultivation of students' educational practice ability, and scientifically construct a comprehensively-targeted modular teaching skills training content system.

\subsection{Constructing the "CUGS" cooperative school-running mode and the student's "double tutors" training mechanism}

In view of the practical problems such as the shortage of teaching skills training equipment and places, the shortage of educational practice bases, and the shortage of teachers who study teaching materials and teaching methods in middle schools, we can explore the construction of "CUGS" cooperative school-running mode and establish 'double tutors' system for students. The "CUGS" cooperative school-running mode is to jointly run schools with key normal universities, local education departments, well-known local middle schools. Through the "CUGS" cooperative school-running, we can rely on the discipline research advantages of key normal universities to enrich the cutting-edge knowledge and latest research achievements in practical education into teaching skills training. We can jointly formulate teaching skills training content and training programs, share the educational practice resources of local education departments, primary and secondary schools, for improving students' educational research ability and teaching skills level. Students' "double tutors" are college tutors and middle school front-line backbone tutors. College tutors give guidance on subject knowledge and educational theory to cultivate good theoretical basis of teaching skills, while middle school front-line tutors give practical guidance on teaching skills to cultivate students' practical ability of educational skills.

\subsection{Constructing the whole process "spiral" educational practice teaching mechanism}

A certain level of teaching skills needs to be formed by accumulating what you have learned, considered and thought during daily study and practice, and it needs to follow certain growth rules. Teaching skills training should run through the whole process of undergraduate training, and "spiral" educational practice can be adopted to further strengthen the educational practice. Educational probation and teaching skills training tasks should be arranged for a certain period of time in four semesters from sophomore to junior. A one-semester educational practice course should be carried out for senior students according to the usual practice. The education and training objectives of each stage should be set by modules, so as to ensure the effectiveness of teaching skills training.

\subsection{Building a network platform for school teaching skills training and make good use of micro- teaching places}

In order to enable students to learn independently in their spare time, we can build a network platform for school teaching skills training, establish a corresponding database of teaching skills training cases and a reward system for learning exchange. As a result, students can independently observe and learn excellent teaching case videos and related teaching skills training materials, and record relevant achievements. It can realize the training tasks of instructors through the network platform, and finally submit them for review. At the same time, guiding students to make good use of microteaching places and strengthening micro-teaching training for normal students are the basic guarantee for normal students to skillfully use teaching skills. In micro-teaching, we make full use of audio-visual equipment to record and evaluate the training process of students' teaching skills, so that students' teaching skills are constantly improved and tend to be stable.

\subsection{Establishing a teaching skill training mode of "class group + competition + workshop"}

In the process of teaching skills training, we should make full use of various forms to arouse students' enthusiasm to participate in activities such as practice, discussion and comment, so that they can master basic teaching skills. The teaching skill training mode of "class group + competition + workshop" can be constructed through the coordination and organization of the secondary teaching institute of the school, i.e. the trinity teaching skill training mode of "class and league branch activities promote students' independent training — teaching skill training courses and workshops lead — discipline teaching skill competition promotes".

\subsection{Exploring the establishment of a scientific and reasonable evaluation mechanism}

Implement the evaluation system of teaching skills and abilities up to standard, formulate the evaluation standard of each teaching skills and abilities training, assess students' abilities up to standard in stages, and adopt qualitative and quantitative evaluation methods in the training process. Qualitative evaluation points out advantages and disadvantages for improvement, while quantitative evaluation gives quantitative results to record scores. Establish a record book (card) of students' teaching skills training activities, and gradually improve the assessment and evaluation mechanism combining various assessments. Inviting relevant experts inside and outside the school to evaluate each process and stage of teaching skills training in various stages, on the basis of expert evaluation, fine-tuning the training process and assessment 
mechanism in a timely manner to enhance the adaptability and pertinence of training.

\section{Conclusion}

In view of the situation of newly-built local undergraduate colleges is different, and the development of disciplines and specialties has its own characteristics. Therefore, some conclusions need further study. This study is based on the construction of teaching skills training mode for normal students in newly-built local universities, and tries to improve the teaching skills of normal students by exploring the training mode, such as the content system of teaching skills training, the 'CUGS' cooperative education mode, the training mechanism of students' 'double tutors' system, the whole process 'spiral' educational practice teaching mechanism, the teaching skills training network platform, the teaching skills training mode of 'class group + competition + workshop' and evaluation mechanism.

\section{Acknowledgments}

This paper is supported by Teaching Reform Project of Guizhou Institute of Engineering and Applied Technology. I am deeply indebted to all the team members, who offered invaluable advice and comments.

\section{Conflicts of interest}

The authors declare no conflicts of interest regarding the publication of this paper.

\section{References}

[1] The Teacher Training Department of the Ministry of Education of the People's Republic of China. The basic requirements for teachers' professional skills training for students of higher normal colleges (trial);1992.

[2] The Teacher Training Department of the Ministry of Education of the People's Republic of China. The syllabus for teacher professional skills training for students in higher normal schools (trial);1994.

[3] Ministry of Education of the People's Republic of China. Opinions on vigorously promoting the reform of teacher education curriculum; 2011.

[4] Ministry of Education of the People's Republic of China. Interim Measures for the Qualification Examination for Primary and Secondary School Teachers; 2013.

[5] Liu, L.P., \& Wang, Q. The promotion strategy of teacher training students' professional skill training-Taking X Normal University as an example. Teacher Education Research. 2019; (3).

[6] Wang, H. Y. Problems and countermeasures in teaching skills of normal students. Educational Exploration. 2013; (12).

[7] Chen, W. J. An analysis of the imbalance between the supply and demand of teacher education courses-based on a survey of normal students in a comprehensive university. Educational Exploration. 2018; (6).

[8] Jiang Ping. Crisis and Countermeasures of Teacher's to Normal Education. Education and Teaching Research. 2017; (8). 